\title{
Vitamin c protects against viper venom induced hepatotoxicity and oxidative damage in rat liver
}

\begin{abstract}
Snake bite is one of the major causes of death around the globe and a major clinical concern due to improper prognosis as a result of the unavailability of research data. The effect of one sub-lethal dose ( $4 \mathrm{mg} / \mathrm{kg}$ body weight) of Bitis arietans crude venom on serum solute/trace element levels and various markers for tissue damage in rat liver have been investigated. Bitis arietans venom caused significant perturbation in the serum levels of electrolytes sodium and potassium and also in the copper: zinc ratio. There was profound hepatotoxicity and nephrotoxicity as evident by increased levels of marker enzymes AST and metabolites creatinine and blood urea nitrogen. This was associated with significant increase in the levels of lipid peroxidation in the liver and concomitant perturbation in the antioxidant enzyme activities. When vitamin $\mathrm{C}(50 \mathrm{mg} / \mathrm{kg}$ body weight) was given along with the venom we witnessed a significant ameliorative effect. There was marked improvement in serum levels of hepatic marker enzyme AST and creatinine and urea. Although there was improvement in the levels of copper and zinc upon vitamin $\mathrm{C}$ treatment we observed a significant improvement in the sodium: potassium ratio after $24 \mathrm{hrs}$. Vitamin C treatment also significantly reduced the level liver lipid peroxidation and improved the activities of antioxidant enzymes. Taken together our results indicate that viper venom causes oxidative damage to the liver and these effects can be counteracted by the use of an antioxidant.
\end{abstract}

Volume 2 Issue I - 2016

\begin{abstract}
Wasim Khan MD, Nasreddin Abdo Osman, AbdulazizMushabbab Alahmari, Amel Amaan, Abdulrahman Al-Asmari
\end{abstract}

Research Centre, Riyadh Military Hospital, Saudi Arabia

Correspondence: Md.Wasim Khan, Division of Cell Biology \& Physiology, Research Centre, Riyadh Military Hospital, Saudi Arabia,Tel+919748529884, Email wasim.khan@iicb.res.in

Received: August 06, 2015 | Published: January 07, 2016

Keywords: oxidative stress, vitamin c, copper/zinc ratio, snake venom

Abbreviations: RPM, revolutions per minute; AST, serum aspartate aminotransferase; ALT, serum glutamate pyruvate transaminase; Scr, serum creatinine; BUN, blood urea nitrogen; C, control; V, venom; VC, vitamin; VVC, venom+vitamin c ; TBS, tris buffered saline; SOD, superoxide dismutase; Cat, catalase; GSH-Px, glutathione peroxidase; LPO, lipid peroxidation

\section{Introduction}

Morbidity and mortality due to snakebite is an important socio medical problem throughout the globe, particularly in the rural areas. The local manifestations caused by viper's venoms include edema pain, hemorrhage, and necrosis. ${ }^{1-3}$ Viper's venom has been implicated in multiple pathologies including neurotoxicity, ${ }^{4}$ nephrotoxicity ${ }^{5,6}$ lung toxicity, ${ }^{7}$ hepatotoxicity ${ }^{8}$ and cardiotoxicity. ${ }^{9}$ Bitis arietans species is responsible for more snakebite fatalities than any other African snake largely owing to its wide distribution, common occurrence, size, potent venom being produced in large amounts and their frequent encounter with humans. ${ }^{10-12}$ The cytotoxic venom ${ }^{13}$ is one of the most toxic in the viperidae family. In humans, bites from this species can produce severe local and systemic symptoms. Based on the degree and type of local effect, bites can be divided into two symptomatic categories: those with little or no surface extravasation, and those with hemorrhages evident as ecchymosis, bleeding and swelling. In both cases there is severe pain and tenderness, but in the latter there is widespread superficial or deep necrosis and compartment syndrome. ${ }^{11-15}$ Serious bites results in significant hemorrhage or coagulation in the affected muscles. ${ }^{10-12}$ The fatality rate highly depends on the severity of the bites and some other factors. Most fatalities are associated with poor clinical management and neglect. ${ }^{11,12}$

The last two decades have witnessed a major drift in the interests of the scientific community towards providing better means to containing the health risks of the human race. The century old chemotherapies against various disorders have never been a success, albeit not a total failure. Such therapies have a major drawback of side effects that give rise to unseen disorders that emerge as a new challenge. In this regard, the concept of foodstuffs as natural medicines i.e. nutraceuticals has become very attractive. The aim of this study was to investigate the possible beneficial effects of vitamin $\mathrm{C}$ in the first line treatment of Bitis arietans venom in rats.

\section{Materials and methods}

\section{Experimental animals}

Male albino Wistar rats weighing 150-200g maintained on a normal chow diet were used. The animals were divided into four groups viz Control (C), Venom (V), Vitamin C alone (VC) and Venom + Vitamin $\mathrm{C}$ (VVC) with 8-10 animals in each group. Rats were administered $4.0 \mathrm{mg} / \mathrm{kg}$ body weight Bitis arietans venom by subcutaneous (sc) injection. One hour after the injection vitamin C $(50 \mathrm{mg} / \mathrm{kg})$ was administered by oral gavage. The animals were then sacrificed under light ether anesthesia after 3,6 and 24hours; blood was collected and preserved till further analysis. The experimental protocol was approved by the Institutional Research and Ethics Committee.

\section{Reagents}

All reagents were of analytical grade. Only doubly distilled water was used in preparing solutions, for use as blanks, and for rinsing the equipment. All glass wares were thoroughly cleaned with dilute $0.1 \mathrm{M}$ $\mathrm{HNO}_{3}$ and rinsed well.

\section{Venom}

The venom used in this study was collected from Bitis arietans snakes, housed and milked by professionals at the Department of 
Zoology, King Saud University, Riyadh. The fresh venom was filtered and then lyophilized and stored in dark at $4^{\circ} \mathrm{C}$. A stock solution of venom $(10 \mathrm{mg} / \mathrm{mL})$ was prepared in saline and used in this study.

\section{Serum chemistries}

Blood samples were collected at the time of sacrificing the animals and serum was separated by centrifuging at 3000 revolutions per $\min (\mathrm{RPM})$ and stored at $-20^{\circ} \mathrm{C}$ until further use. Serum aspartate aminotransferase (AST), serum glutamate pyruvate transaminase (ALT), Serum creatinine (Scr) and blood urea nitrogen (BUN) were determined by commercially available kits from United Diagnostics Industry, Dammam, Saudi Arabia.

\section{Preparation of liver homogenate}

The liver samples kept in ice-cold Tris buffered saline (TBS) were homogenized in a glass Teflon homogenizer in $10 \mathrm{mM}$ Tris-HCl buffer ( $\mathrm{pH} 7.5)$ to get $10 \%(\mathrm{w} / \mathrm{v})$ homogenate followed by high-speed homogenization in an Ultra Turrex Kunkel homogenizer. Aliquots of liver homogenates were divided into three parts. Homogenate was centrifuged at 5000 revolutions per min for $15 \mathrm{~min}$ at $4^{\circ} \mathrm{C}$ and supernatant was used for assay of free-radical scavenging enzymes and the crude homogenate was used for the estimation of total thiol (-SH) and lipid peroxidation.

\section{Atomic absorption standards}

In all experiments readymade standards from Perkin Elmer were used. A Perkin Elmer atomic absorbance spectrophotometer (Model A Analyst 800) equipped with an auto-sampler was used in all experiments.

\section{Trace metal determination}

Copper and zinc were assessed by the method of Henkin \& Meret. ${ }^{16}$ Sodium and Potassium were determined by the method of Kahn and Fernandez.$$
\text { A }
$$

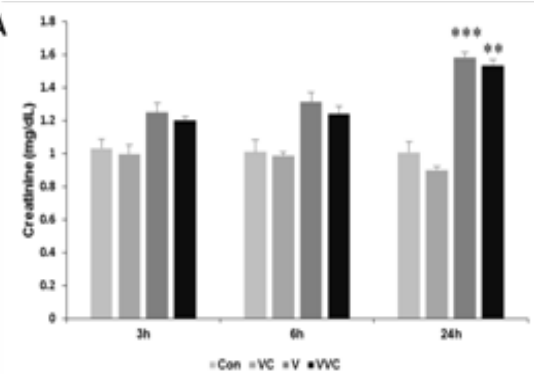

C

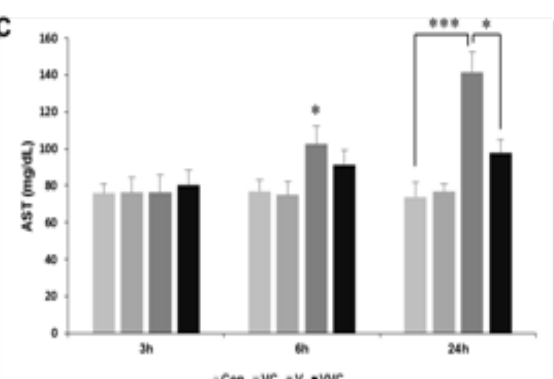

\section{Assay of enzymatic and non-enzymatic antioxidants}

Superoxide dismutase (SOD) was assayed by the method of Marklund \& Marklund. ${ }^{17}$ Catalase (Cat) and glutathione peroxidase (GSH-Px) activities were determined by the method of Giri et al., ${ }^{18}$ and Flohe \& Gunzler, ${ }^{19}$ respectively. Total -SH was determined by the method of Sedlak and Lindsay ${ }^{20}$ and lipid peroxidation by the method of Ohkawa et al. ${ }^{4}$ Protein concentrations in the homogenates were determined the method of Lowry et al., ${ }^{21}$ as modified by Yusufi et al. ${ }^{22}$

\section{Statistical analysis}

Study groups were compared for variance by one way ANOVA using SPSS 14.0 (SPSS Inc., Chicago, IL, USA). The data were expressed as mean $\pm \mathrm{SEM} ; \mathrm{p}<0.05$ was considered as significant, $\mathrm{p}<0.01$ as highly significant and $\mathrm{p}<0.001$ as extremely significant. Appropriate post-hoc tests were applied were necessary.

\section{Results and discussion}

\section{Bitis arietans venom causes profound damage to kidney and liver tissues}

Venom from the viperidae family of snakes in very well documented to cause severe local damage to tissues especially near the actual site of the snake bite. We used a sub lethal dose of Bitis arietans venom to assess the tissue damaging capability of the venom. We found that the venom causes profound and significant damage to the renal and hepatic tissues after 24 hours of treatment as assessed by the increase in the serum levels of creatinine, blood urea nitrogen and liver enzymes such as AST (Figure 1). In groups where Vitamin $\mathrm{C}$ was administered to rats along with the venom we found that there was a significant reduction in the serum levels of blood urea nitrogen and AST. This indicates to a possible protective effect conferred by Vitamin $\mathrm{C}$ in snake bite.
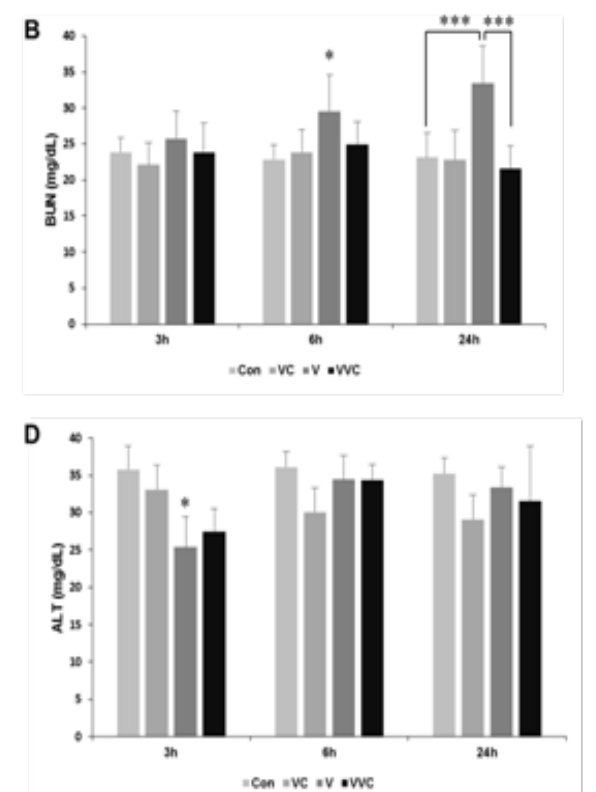

Figure I Effect of venom and vitamin C on serum parameters of hepato/nephrotoxicity.

A-D Rats were treated with venom $(4 \mathrm{mg} / \mathrm{kg})$ and vitamin $\mathrm{C}$ as mentioned in Methods. Blood was collected by heart puncture and serum was collected. All parameters were evaluated with commercially available kits according to manufacturer's instructions.All panels: $\mathrm{n}=8-\mathrm{I} 0$, ${ }^{\mathrm{p}} \mathrm{p}<0.05$, $* * \mathrm{p}<0.0 \mathrm{I}, * * * \mathrm{p}<0.00 \mathrm{I}$ compared to Control. 


\section{Effect of Vitamin $\mathrm{C}$ on serum electrolytes $\mathrm{Na}$ K ratio/ serum Copper, Zinc and $\mathrm{Cu}: Z n$ ratio after venom administration}

The trace-element content of tissues, blood, hair, nails, and excreta of sick and healthy human beings has been studied in relation to a number of diseases (other than nutritional derangements) such as leukemia, multiple sclerosis, diabetes, azotaemia, hepatolenticular degeneration, schizophrenia, ${ }^{23,24}$ cancer, ${ }^{23-25}$ liver diseases, ${ }^{24,26,27}$ parkinsonism, ${ }^{22,24}$ cystic fibrosis a and others, including cardiovascular diseases, in an attempt to ascertain the existence of a relationship between disease and abnormal trace-element concentration in the human body. In some instances a direct relationship has been found between changes in tissue mineral content and the severity, duration, or incidence of a disease. Although such changes may be secondary to the degeneration and are not a proof of a real cause-effect relation, yet they might afford clues as to the role played by trace elements in the pathogenesis of a given disease; they might also have a predictive

A

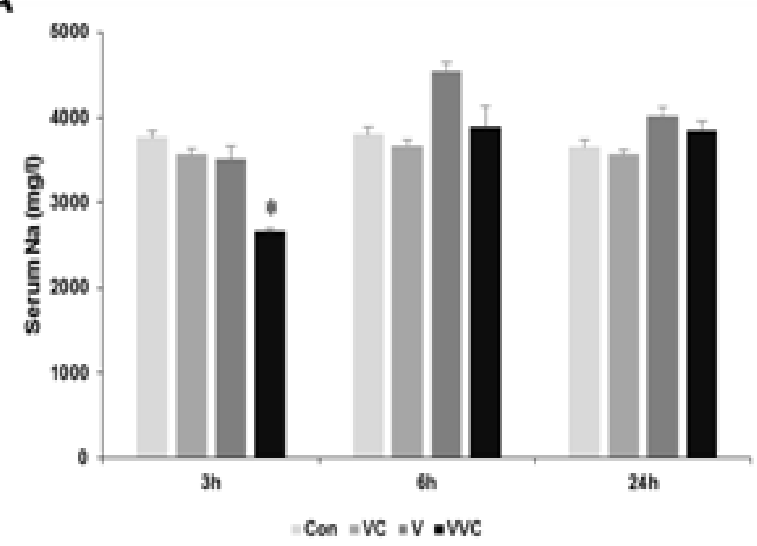

value. We have previously shown that the ratio of $\mathrm{Na}: \mathrm{K}$ and $\mathrm{Cu}: \mathrm{Zn}$ significantly changes upon venom administration. ${ }^{28}$ The concentration of serum electrolytes i.e. Sodium $(\mathrm{Na})$ and Potassium $(\mathrm{K})$ was estimated by Atomic absorbance spectrophotometry. We observed that there was no significant change in serum $\mathrm{Na}$ at $3 \mathrm{hrs}$ and $24 \mathrm{hrs}$ post venom administration but a highly significant increase in $\mathrm{Na}$ concentration was observed at $6 \mathrm{hrs}$ post venom administration (Figure 1). Potassium concentration decreased significantly after 6 hours giving an inverse relation with the concomitant increase in Sodium concentration at the same time. Furthermore, potassium concentration also decreased significantly in serum after $24 \mathrm{hrs}$ of venom administration. The Na:K ratio which signifies renal malfunction increased significantly after 6 hours post venom administration (Figure2). When vitamin $\mathrm{C}$ was administered along with viper venom we observed that it largely affects the levels of potassium in serum (Figure 2). After 24 hours of treatment vitamin $\mathrm{C}$ was able to bring the $\mathrm{Na}: \mathrm{K}$ ratio back close to the normal range (Figure 2).
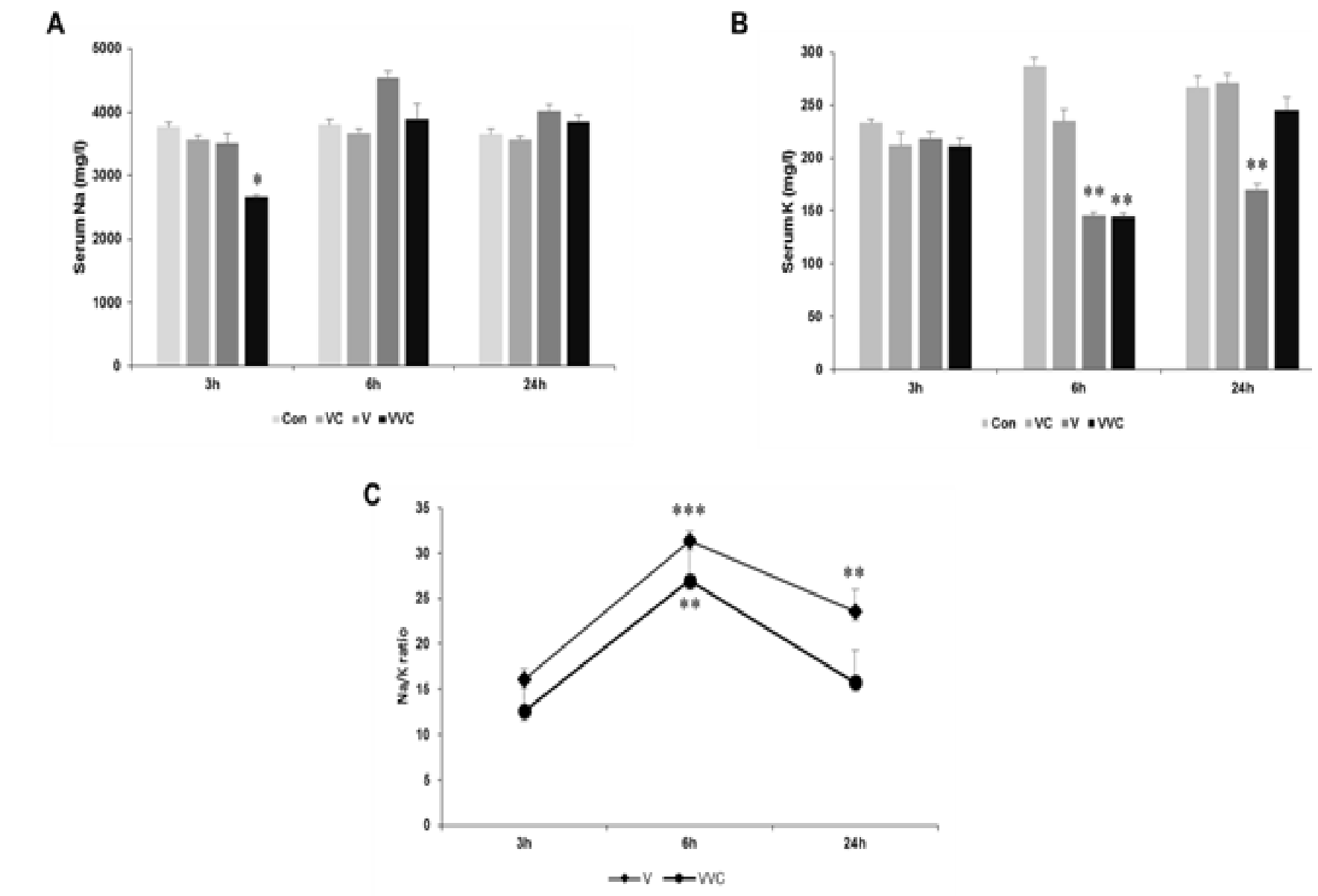

Figure 2 Effect of venom and vitamin $\mathrm{C}$ on serum $\mathrm{Na}$ and $\mathrm{K}$ levels.

A-B Rats were treated with venom $(4 \mathrm{mg} / \mathrm{kg})$ and vitamin $\mathrm{C}$ as mentioned in Methods. Blood was collected by heart puncture and serum was collected. Serum levels of sodium and potassium were analyzed using atomic absorption spectrophotometry as described in Methods. C.

Data from Figure 2A-B was used to calculate the ratio of Na:K.All panels: $n=8-10,{ }_{p}^{*}<0.05$, ${ }^{*} p<0.01$, ${ }^{* * *} p<0.00$ I compared to Control.

Serum copper concentrations first tend to decrease at $3 \mathrm{hrs}$ and $6 \mathrm{hrs}$ post venom administration but then it elevated drastically after $24 \mathrm{hrs}$ venom administration. There was no significant change in the levels of zinc in serum post venom administration but there was an extremely significant decrease after $24 \mathrm{hrs}$. The $\mathrm{Cu}: \mathrm{Zn}$ ratio is considered as a biomarker in the pathophysiology of various types of cancers and other pathologic conditions. We observed an extremely significant increase in the $\mathrm{Cu}: \mathrm{Zn}$ ratio after $24 \mathrm{hrs}$ of venom administration (Figure 3) but the administration of Vitamin $\mathrm{C}$ did not affect the rise in the $\mathrm{Cu}: \mathrm{Zn}$ ratio. 


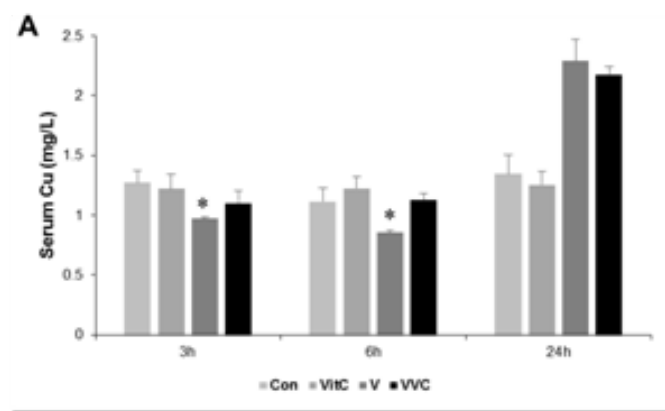

B
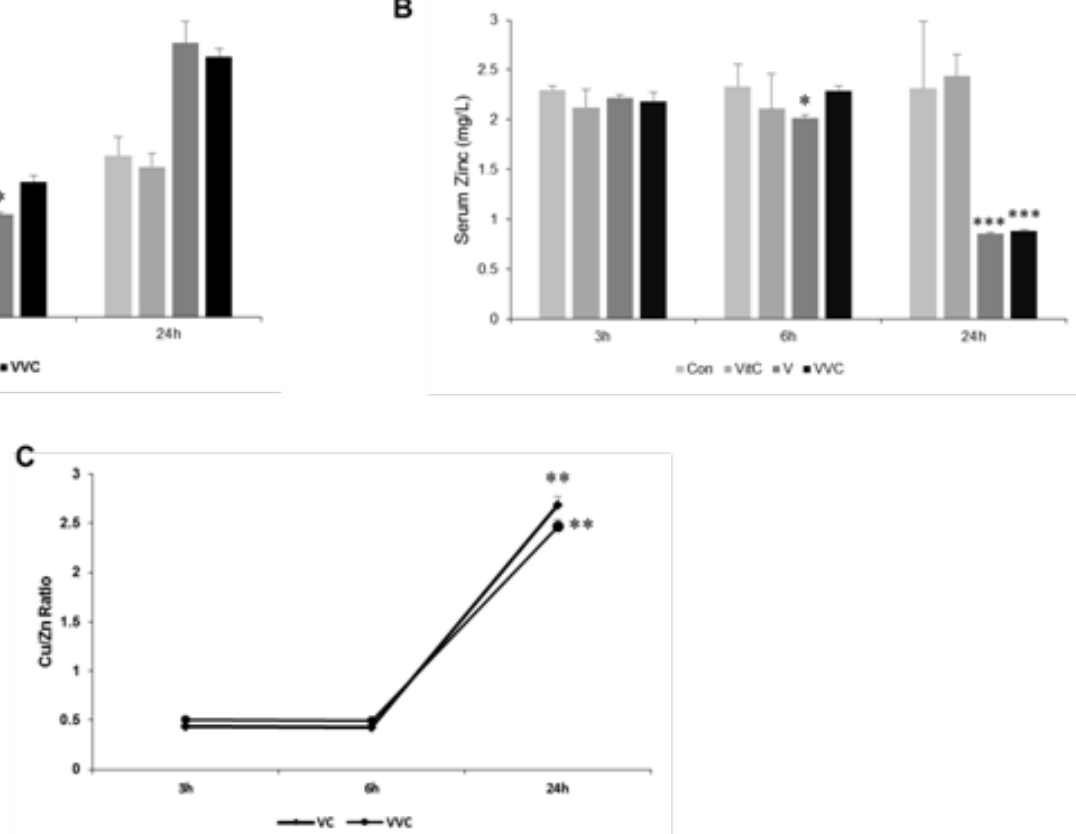

Figure 3 Effect of venom and vitamin $\mathrm{C}$ on serum $\mathrm{Cu}$ and $\mathrm{Zn}$ levels.

A-B Rats were treated with venom $(4 \mathrm{mg} / \mathrm{kg})$ and vitamin $C$ as mentioned in Methods. Blood was collected by heart puncture and serum was collected. Serum levels of copper and zinc were analyzed using atomic absorption spectrophotometry as described in Method C.

Data from Figure 3A-B was used to calculate the ration of Cu:Zn. All panels: $n=8-10,{ }^{*}<<0.05,{ }^{* *} p<0.01$, *** $p<0.00$ I compared to Control.

\section{Vitamin $C$ administration protects against hepatic tissue damage induced by viper venom}

There is considerable evidence in the scientific literature that snake venom particularly those belonging to the Viper family produces significant amount of tissue damage at the site of bite as well as systemically. To prove whether Bitis arietans induces damage to the liver tissue we checked for lipid peroxidation (LPO) which takes into account the amount of thiobarbituric acid reactive substances formed. Our data indicates that LPO increased with time in rats administered with Bitis venom with significant increase in 24 hours. Interestingly however in rats where Vitamin $\mathrm{C}$ was administered along with the venom there was a significant reduction in LPO as compared to the venom group (Figure 4). We could not find any significant changes in the total sulphydryl content of the liver homogenates (Figure 4). Increase in LPO is generally associated with disturbances in the antioxidant enzyme systems so we next thought to analyses the important antioxidant enzymes such as superoxide dismutase (SOD), catalase (CAT) and glutathione peroxidase (GSH-Px) (Figure 5). Our results indicate that although there was no evident change in the enzyme activities of SOD, there was a profound increase in the activity of CAT whenever Vitamin $\mathrm{C}$ was administered along with venom (Figure 5). The activity of GSH-Px showed a marked decrease when venom alone was administered to rats and more importantly Vitamin $\mathrm{C}$ was able to significantly increase the specific activity (Figure 5).

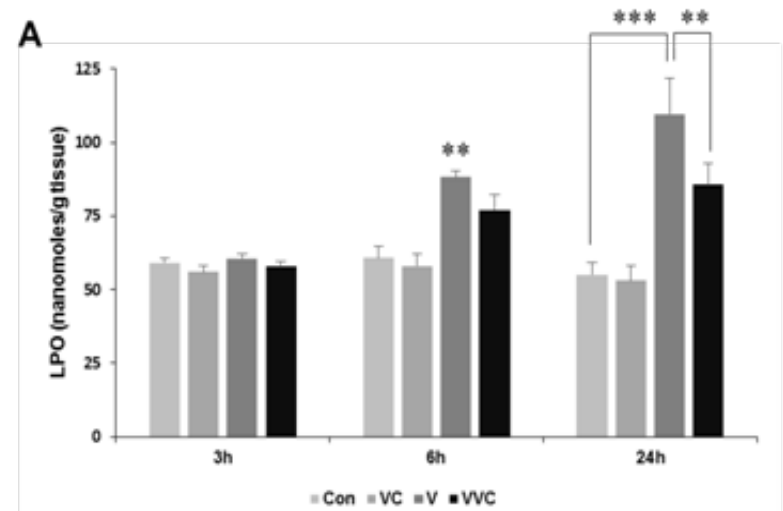

B

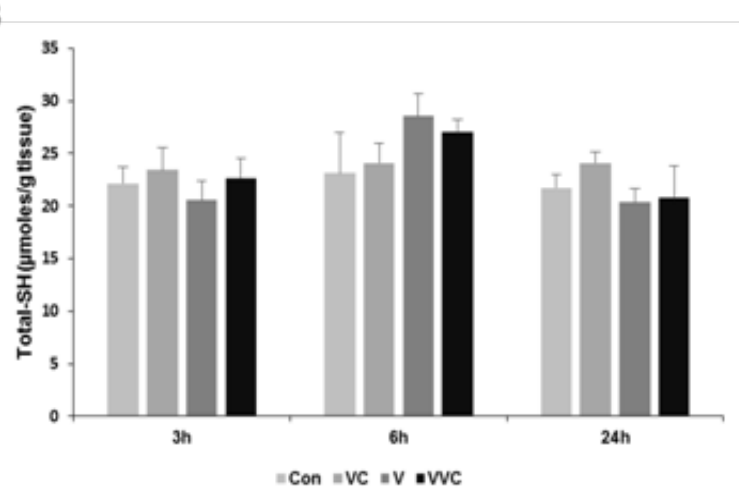

Figure 4 Effect of venom and vitamin $C$ on non-enzymatic antioxidants and $L P O$.

A-B Rats were treated with venom $(4 \mathrm{mg} / \mathrm{kg})$ and vitamin $\mathrm{C}$ as mentioned in Methods. Liver was collected after sacrifice and homogenized as described in methods. The liver homogenates were used to determine levels of LPO and SH. $n=8-10,{ }^{*} \mathrm{p}<0.05$, **p $<0.01$, *** $<<0.00$ I compared to Control. 

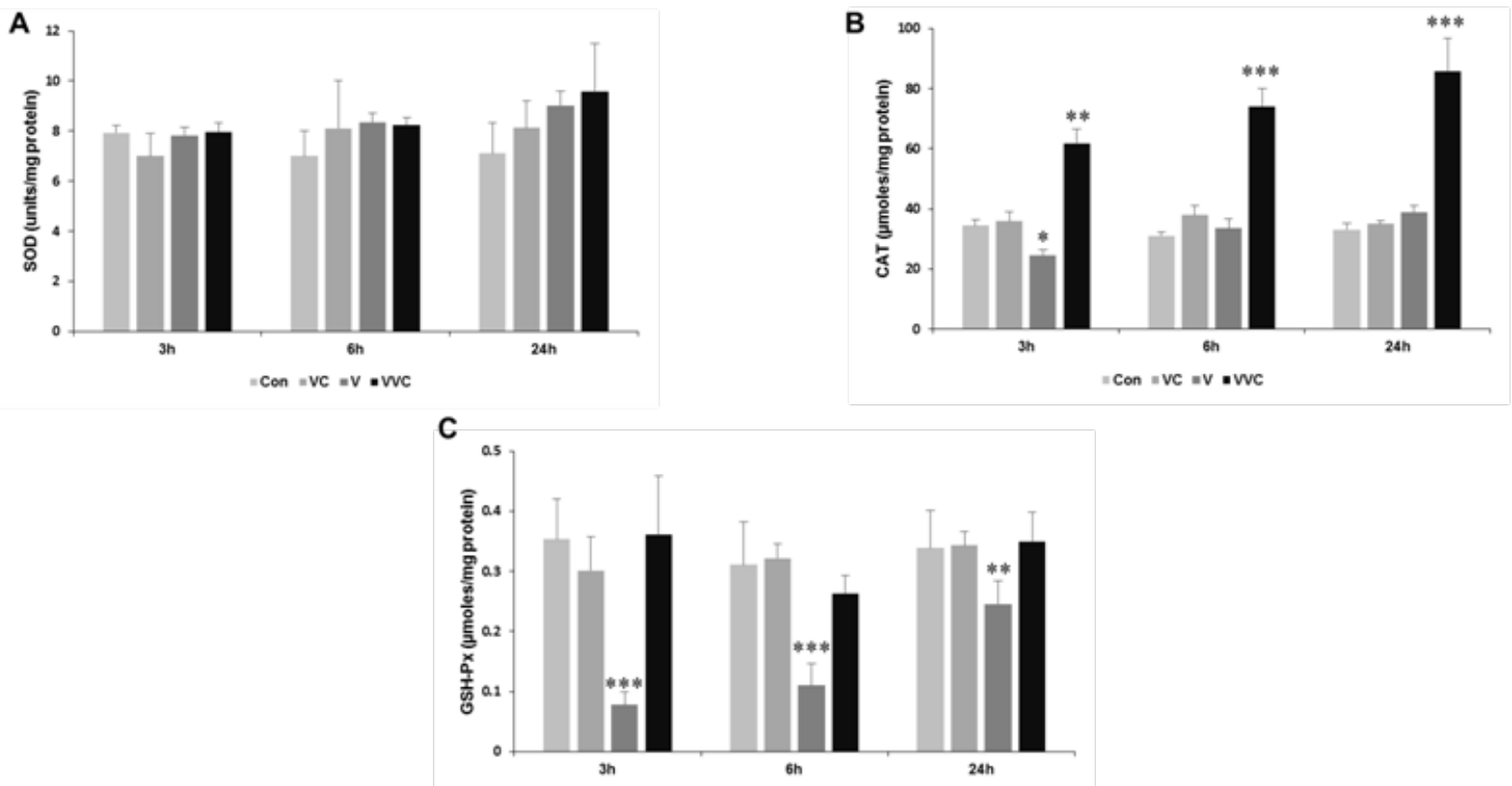

Figure 5 Effect of venom and vitamin $C$ on enzymatic antioxidants.

A-C Rats were treated with venom $(4 \mathrm{mg} / \mathrm{kg})$ and vitamin $\mathrm{C}$ as mentioned in Methods. Liver was collected after sacrifice and homogenized as described in methods. The liver homogenates were used to determine levels antioxidant enzyme activities. $n=8-10,{ }^{*} p<0.05,{ }^{*} p<0.0 I, * * * p<0.00$ I compared to Control.

\section{Conclusion}

We therefore show that Vipers venom causes tissue damage by increasing free radical mediated damage and that this can be controlled by the administration of antioxidants. This is of profound importance since the first line of intervention that is available in cases of snake bites is anti-venom therapy which itself is harmful to the body. We therefore propose the use of antioxidants along with antivenom therapy for enhanced clinical care.

\section{Acknowledgements}

None.

\section{Conflict of interest}

The author declares no conflict of interest.

\section{References}

1. Warrell DA. Venomous bites and stings in Saudi Arabia. Saudi Med J. 1993;14:196-202.

2. Kamiguti AS, Cardoso JL, Theakston RD, et al. Coagulopathy and haemorrhage in human victims of Bothrops jararaca envenoming in Brazil. Toxicon. 1991;29(8):961-972.

3. Kingston ME. Management of snake bite in Saudi Arabia. King Faisal Specialist Hosp Med J. 1981;1:87-94.

4. Ohkawa H, Ohishi N, Yagi K. Assay for lipid peroxides in animal tissues by thiobarbituric acid reaction. Annals of Biochemistry. 1979;95(2):351358 .

5. Petan T, Krizaj I, Gelb MH, et al. Ammodytoxins, potent presynaptic neurotoxins, are also highly efficient phospholipase A2 enzymes. Biochemistry. 2005;44(37):12535-12545.
6. Chaiyabutr N, Sitprija V. Pathophysiological effects of Russell's viper venom on renal function. J Nat Toxins. 1999;8(3):351-358.

7. de Castro I, Burdmann EA, Seguro AC, et al. Bothrops venom induces direct renal tubular injury: role for lipid peroxidation an prevention by antivenom. Toxicon. 2004;43(7):833-839.

8. Uma B, Veerabasappa Gowda T. Molecular mechanism of lung hemorrhage induction by VRV-PL-VIIIa from Russell's viper (Viperarusselli) venom. Toxicon. 2000;38(8):1129-1147.

9. Mukherjee AK, Maity CR. Effect of dietary supplementation of vitamin $E$ in partial inhibition of Russell's viper venom phospholipase A2 induced hepatocellular and microsomal membrane damage in rats. Acta Physiol Hung. 1998;85(4):367-374.

10. Unkovic-Cvetkovic N, Cvetkovic M, Petkovic D, et al. Histopathological changes in rat myocardium caused by Vipera ammodytes (European viper) snake venom. Toxicon. 1983;21(3):429-432.

11. Mallow D, Ludwig D, Nilson G. True Vipers: Natural History and Toxinology of Old World Vipers. USA: Krieger Publishing Company; 2003. 359 p.

12. Spawls S, Howell K, Drewes R, et al. A Field Guide to the Reptiles of East Africa. England: A \& C Black Publishers Ltd; 2004. 543 p.

13. Bitisarietans. Integrated Taxonomic Information System. 2006.

14. Spawls S, Branch B. The Dangerous Snakes of Africa. Ralph 13 Curtis Books. Dubai: Oriental Press; 1995. 192 p.

15. Widgerow AD, Ritz M, Song C. Load cycling closure of fasciotomies following puff adder bite. European Journal of Plastic Surgery. 1994;17(1):40-42.

16. Meret S, Henkin RI. Simultaneous direct estimation by atomic absorption spectrophotometry of copper and zinc in serum, urine, and cerebrospinal fluid. Clin Chem. 1971;17(5):369-373. 
17. Marklund S, Marklund G. Involvement of the superoxide anion radica in the auto oxidation of pyrogallol and a convenient assay for superoxide dismutase. European J of Biochem. 1974;47(3):469-474

18. Giri U, Iqbal M, Athar M. Porphyrin-mediated photosensitization has a weak tumor promoting activity in mouse skin:possible role of in-situ generated reactive oxygen species. Carcinogenesis. 1996;17(9):20232028.

19. Flohe L, Gunzler W. Assay of glutathione peroxidase. In: Colowick SP, Kaplan NO, editors. New York: Academic Press; 1984. 105:114-121.

20. Sedlak J, Lindsay RH. Estimation of total protein bound and non protein bound SH groups in tissue with Ellman's reagent. Anal Biochem. 1968;25(1):192-205.

21. Lowry $\mathrm{OH}$, Rosenbrough NJ, Farr AL, et al. Protein determination with the Folin phenol reagent. J Biol Chem. 1951;193(1):265-275.

22. Yusufi ANK, Low MG, Turner ST, et al. Selective removal of alkaline phosphatase from renal brush-border membrane and sodium-dependent brush border membrane transport. J Biol Chem. 1983;258(9):56955701
23. Kanabrocki EL, Case LF, Graham L, et al. Manganese and copper levels in human urine. J nucl Med. 1965;6(11):780-791.

24. Kanabrocki EL, Case LF, Graham L, et al. Non-dialyzable manganese and copper levels in serum of patients with various diseases. J nucl Med. 1967;8(3):166-172.

25. Samsahl K, Brune D, Wester P0. Simultaneous determination of 30 trace elements in cancerous and non-cancerous human tissue samples by neutron activation analysis. Int J appl Radiat. 1965;16:273-281.

26. Martin GM. Copper content of hair and nails of normal individuals and of patients with hepatolenticular degeneration. Nature. 1964;202:903904

27. Hunt AH, Parr RM, Taylor DM, et al. Relation between cirrhosis and trace metal content of liver with special reference to primary biliary cirrhosis and copper. Brit med J. 1963;2(5371):1498-1501.

28. Mindadse AA, Tschikowani TI. On the distribution of trace elements (manganese, copper, zinc, and gold) in serum and cerebrospinal fluid in epilepsy and parkinsonism. Dtsch Gesundheitsw. 1967;22(37):17461748 . 